\title{
Etching Characteristics and Changes in Surface Properties of IGZO Thin Films by $\mathrm{O}_{2}$ Addition in $\mathrm{CF}_{4} /$ Ar Plasma
}

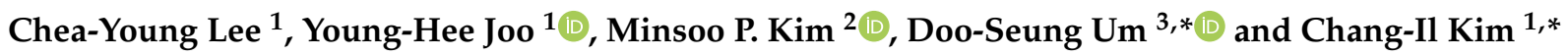 \\ 1 School of Electrical and Engineering, Chung-Ang University, Seoul 06974, Korea; \\ dino94313@cau.ac.kr (C.-Y.L.); ston10000@cau.ac.kr (Y.-H.J.) \\ 2 School of Energy and Chemical Engineering, Ulsan National Institute of Science and Technology (UNIST), \\ Ulsan 44919, Korea; pureego@unist.ac.kr \\ 3 Department of Electrical Engineering, Sejong University, Seoul 05006, Korea \\ * Correspondence: dsum@sejong.ac.kr (D.-S.U.); cikim@cau.ac.kr (C.-I.K.)
}

check for

updates

Citation: Lee, C.-Y.; Joo, Y.-H.; Kim, M.P.; Um, D.-S.; Kim, C.-I. Etching Characteristics and Changes in Surface Properties of IGZO Thin Films by $\mathrm{O}_{2}$ Addition in $\mathrm{CF}_{4} / \mathrm{Ar}$ Plasma. Coatings 2021, 11, 906. https://doi.org/10.3390/ coatings11080906

Academic Editor: Francesco Di Quarto

Received: 24 June 2021

Accepted: 26 July 2021

Published: 29 July 2021

Publisher's Note: MDPI stays neutral with regard to jurisdictional claims in published maps and institutional affiliations.

Copyright: (c) 2021 by the authors. Licensee MDPI, Basel, Switzerland. This article is an open access article distributed under the terms and conditions of the Creative Commons Attribution (CC BY) license (https:/ / creativecommons.org/licenses/by/ $4.0 /)$.

\begin{abstract}
Plasma etching processes for multi-atomic oxide thin films have become increasingly important owing to the excellent material properties of such thin films, which can potentially be employed in next-generation displays. To fabricate high-performance and reproducible devices, the etching mechanism and surface properties must be understood. In this study, we investigated the etching characteristics and changes in the surface properties of $\mathrm{InGaZnO}_{4}(\mathrm{IGZO})$ thin films with the addition of $\mathrm{O}_{2}$ gases based on a $\mathrm{CF}_{4} / \mathrm{Ar}$ high-density-plasma system. A maximum etch rate of $32.7 \mathrm{~nm} / \mathrm{min}$ for an IGZO thin film was achieved at an $\mathrm{O}_{2} / \mathrm{CF}_{4} / \mathrm{Ar}(=20: 25: 75 \mathrm{sccm})$ ratio. The etching mechanism was interpreted in detail through plasma analysis via optical emission spectroscopy and surface analysis via $\mathrm{X}$-ray photoelectron microscopy. To determine the performance variation according to the alteration in the surface composition of the IGZO thin films, we investigated the changes in the work function, surface energy, and surface roughness through ultraviolet photoelectron spectroscopy, contact angle measurement, and atomic force microscopy, respectively. After the plasma etching process, the change in work function was up to $280 \mathrm{meV}$, the thin film surface became slightly hydrophilic, and the surface roughness slightly decreased. This work suggests that plasma etching causes various changes in thin-film surfaces, which affects device performance.
\end{abstract}

Keywords: IGZO; adaptively coupled plasma (ACP); OES; XPS; etch rate; UPS; work function; adhesion

\section{Introduction}

In the development of the next-generation organic light emitting diode-based displays with a high resolution, high scan rate, and mechanical flexibility, amorphous oxide semiconductor-based thin film transistors (OSTFTs) can potentially be employed as switching devices for backplanes [1,2]. Among many candidates, $\mathrm{InGaZnO}_{4}(\mathrm{IGZO})$ is a reliable channel material owing to several remarkable properties, such as high mobility [2-5], high transmittance due to its wide band gap [6,7], high stability against electrical stress owing to strong ion bonding [8], excellent film uniformity [9], low fabrication temperature [10,11], and mechanical flexibility [12-14]. In particular, many studies have focused on IGZObased TFTs because their mechanical flexibility and low-temperature processing enable the realization of flexible display systems.

The demand for high-resolution and large-area displays has led to a decrease in the size of TFT devices $[15,16]$. The bottlenecks to device scaling are the lithography and etching processes. Lithography using the silicon process has been well established, but the etching of IGZO thin films is challenging. Conventional wet etching using chemicals has a high etch rate and selectivity, but it is not suitable for high-resolution patterning processes because of the resulting anisotropy and low uniformity. Therefore, the dry etching process using plasma is preferred, owing to its isotropic etch characteristics and 
high uniformity for high-resolution patterning. Yanbin et al. reported that the etch rate and etch profile of $\mathrm{InGaZnO}_{4}$ thin films depended on the various process parameters, such as gas mixtures and RF power [17]. Kim et al. reported the etching mechanisms of $\mathrm{InGaZnO}_{4}$ thin films in a $\mathrm{CF}_{4} / \mathrm{Ar} / \mathrm{O}_{2}$ inductively coupled plasma system using a Langmuir probe [18]. Although there are many conventional studies on the plasma etching process of IGZO thin films, most of them have focused on the investigation of etch rate, etch selectivity, and the etch mechanism itself [17-20]. However, the composition of the thin-film surface is altered after the etching process by etching residues or implanted atoms [21,22]. This affects the work function, band gap, and surface energy, resulting in a change in device performance $[21,23,24]$. The work function represents the potential required to add or remove electrons from a material (i.e., the potential value required to reach the vacuum level from the Fermi level). Therefore, the work function is an important parameter for charge transfer at the interface. To provide electrons to the channel easily, the metal electrode must have a lower work function than the active layer material. Moreover, the active layer should have a high work function to capture electrons from the electrode [25]. In particular, IGZO has a high work function and low threshold voltage, which can greatly reduce the switching power in n-channel TFTs. Furthermore, the surface energy affects the interconnection with the metal layer. Therefore, surface characteristics after etching have to be elaborately evaluated because the IGZO thin film is involved in the continuous fabrication process [26].

In our previous study, the highest etch rate was obtained at a gas mixing ratio of $\mathrm{CF}_{4} / \mathrm{Ar}=25: 75$ for $\mathrm{CF}_{4} / \mathrm{Ar}$ plasma [27]. We had concluded that the $\mathrm{F}$ in the $\mathrm{CF}_{4} / \mathrm{Ar}$ plasma bonds chemically to form In-F and Zn-F on the surface of the IGZO thin film, and that ion bombardment with Ar ions helped to remove non-volatile byproducts, namely In-F and $\mathrm{Zn}-\mathrm{F}$ from the thin film surface. The addition of $\mathrm{O}_{2}$ to the $\mathrm{CF}_{4} / \mathrm{Ar}$ plasma induced an increase in the number of $\mathrm{F}$ in the plasma. Therefore, in this study, we investigated the etching characteristics resulting from the addition of $\mathrm{O}_{2}$ gas to the $\mathrm{CF}_{4} / \mathrm{Ar}$ plasma. Here, we investigate not only the etching characteristics, but also the changes in the surface properties after the etching of IGZO thin films; these changes result from the addition of $\mathrm{O}_{2}$ gas to $\mathrm{CF}_{4} / \mathrm{Ar}$ plasma. The density of ions and radicals in the plasma was investigated using optical emission spectroscopy (OES), and the change in the chemical composition of the surface was investigated by X-ray photoelectron spectroscopy (XPS). To understand the correlation between the surface composition and work function and to confirm the controllability of the work function by plasma etching, changes in the work function with respect to the surface composition were evaluated using ultraviolet photoelectron spectroscopy (UPS). The surface energy and surface roughness of the thin films were investigated using a contact angle analyzer and atomic force microscopy (AFM), respectively.

\section{Materials and Methods}

Here, 100-150-nm-thick IGZO thin films were grown on a p-type boron-doped (100) silicon substrate using an In:Ga:Zn:O (=1:1:1:4) target with a thickness of 1/8 inch and 2 inches diameter (RND Korea) in an RF sputtering system under the following conditions: $30 \mathrm{sccm}$ Ar inert gas, $60 \mathrm{~W}$ RF power, and $10 \mathrm{mTorr}$ pressure at room temperature. After the deposition of the IGZO thin films, plasma etching was conducted with an $\mathrm{O}_{2} / \mathrm{CF}_{4} / \mathrm{Ar}$ plasma using an adaptively coupled plasma (ACP) system. The ACP system possesses the advantages of a capacitively coupled plasma capacitor structure and an inductively coupled plasma coil, thereby achieving a higher plasma density [15]. The etching process was conducted with a fixed $\mathrm{CF}_{4} / \mathrm{Ar}$ gas ratio $(=25: 75 \mathrm{sccm}), 500 \mathrm{~W}$ source power, $100 \mathrm{~W}$ bias power, and $15 \mathrm{mTorr}$ pressure; further, we changed the additive $\mathrm{O}_{2}$ gas flow rate from 0 to $40 \mathrm{sccm}$. After etching, we measured the etched depth using a depth profiler ( $\alpha$-step 500 , KLA Tencor, Milpitas, CA, USA). Active radicals in the plasma were measured by OES analysis (VT500, Prime Solution, Gunpo-si, Korea). The chemical composition of the surface was investigated through XPS analysis (Sigma Probe, Thermo Fisher Scientific, Waltham, MA, USA) with a fixed retarding ratio mode using $\mathrm{Al}(1486.7 \mathrm{eV})$ and a calibrated 
C 1s binding energy of $284.8 \mathrm{eV}$. The change in the work function according to the surface chemical composition was evaluated via UPS analysis (NEXSA, ThermoFisher Scientific, Waltham, MA, USA) using extreme UV light ( $-10 \mathrm{eV}$ bias voltage), and the results were verified by Kelvin probe force microscope (KPFM) analysis (Multimode V, Veeco, Plainview, NY, USA). The surface roughness and contact angle were estimated via AFM (Quadrexed D3100, Veeco, Plainview, NY, USA) and by using a contact angle analyzer (Phoenix 300, SEO, Suwon-si, Korea), respectively.

\section{Results and Discussion}

Figure $\mathrm{S} 1$ shows the etch rate of the IGZO thin films, depending on the gas mixing ratio of $\mathrm{CF}_{4} / \mathrm{Ar}$ in the inductively coupled plasma (ICP) system; the obtained results were similar to those of the previous study [27]. Figure 1 shows the etch rate of IGZO thin films and etch selectivity to $\mathrm{Al}$ and Photoresist (PR) as a function of the additive $\mathrm{O}_{2}$ concentration under the following fixed conditions: $\mathrm{CF}_{4} /$ Ar gas ratio $=25: 75 \mathrm{sccm}, 500 \mathrm{~W}$ source power, $100 \mathrm{~W}$ bias power, and 15 mTorr pressure. Here, $\mathrm{Al}$ (as well as PR) was chosen to evaluate the etch selectivity as it is widely used as a source or drain electrode in thin-film transistors $[28,29]$. Therefore, we evaluated not only the etch rate, but also the selectivity of IGZO to $\mathrm{Al}$ and PR. As the flow rate of the additive $\mathrm{O}_{2}$ gas increased from 0 to $20 \mathrm{sccm}$, the etch rate of the IGZO thin films increased from 13.1 to $32.7 \mathrm{~nm} / \mathrm{min}$. When the $\mathrm{O}_{2}$ gas flow rate increased further from $20 \mathrm{sccm}$ to $40 \mathrm{sccm}$, the etch rate started to decrease from 32.7 to $16.5 \mathrm{~nm} / \mathrm{min}$. Moreover, the etch selectivity of the IGZO thin films to $\mathrm{Al}$ tended to be similar to the etch rate of the IGZO thin films; the etch selectivity was the highest, at 0.9 , when $\mathrm{O}_{2}$ was added at $20 \mathrm{sccm}$. However, the selectivity for PR decreased as the addition ratio of $\mathrm{O}_{2}$ increased from 0.07 to 0.02 , and the lowest selectivity for PR, 0.02 , occurred when $\mathrm{O}_{2}$ was added at $40 \mathrm{sccm}$.

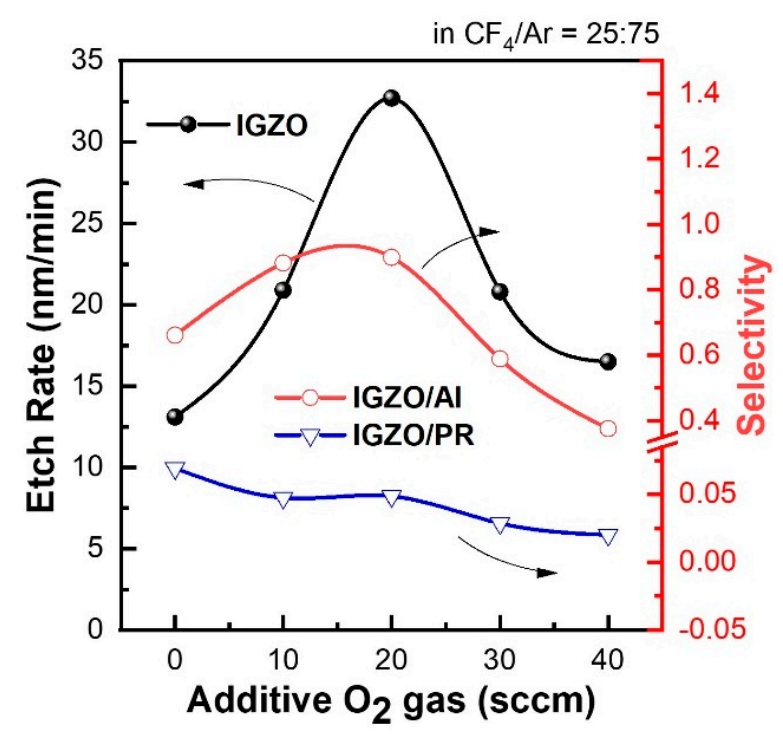

Figure 1. Etch rate of IGZO thin films and etch selectivity to $\mathrm{Al}$ and $\mathrm{PR}$ as a function of additive $\mathrm{O}_{2}$ gas flow rate with fixed $\mathrm{CF}_{4} / \mathrm{Ar}=25: 75 \mathrm{sccm}$. (500 W source power, $100 \mathrm{~W}$ bias power, and 15 mTorr pressure).

The results of the OES analysis provided clues to characterize the plasma state and the mechanisms of the etching process in accordance with changes in the active species [30]. Figure 2 shows the emission intensity of the free radicals in the plasma as the oxygen concentration increased in the $\mathrm{CF}_{4} / \mathrm{Ar}$ plasma, and OES analysis was performed under the same conditions as in Figure 1. Overall, the emission intensity of Ar $(615.49 \mathrm{~nm})$ was steady as the rate of $\mathrm{O}_{2}$ addition increased. However, the $\mathrm{CF}(255 \mathrm{~nm})$ and $\mathrm{CF}_{2}(252.66 \mathrm{~nm})$ decreased gradually as soon as oxygen was added, and they decreased further as the proportion of oxygen gas increased. The emission intensity of $\mathrm{CO}$ was the highest when 
$10 \mathrm{sccm}$ of oxygen was added, decreasing gradually with the further addition of oxygen. The emission intensity of $\mathrm{O}(615.49 \mathrm{~nm})$ increased steadily with the oxygen content. The emission intensity of $\mathrm{F}(685.72 \mathrm{~nm})$ increased rapidly as soon as oxygen was added, and $\mathrm{F}$ showed the highest emission intensity when the oxygen flow rate was $20 \mathrm{sccm}$. As the rate of $\mathrm{O}_{2}$ addition increased to $20 \mathrm{sccm}$, the electron-impact and gas-phase reactions occurred in the $\mathrm{O}_{2} / \mathrm{CF}_{4} /$ Ar plasma, as summarized in Table 1 [31-33].

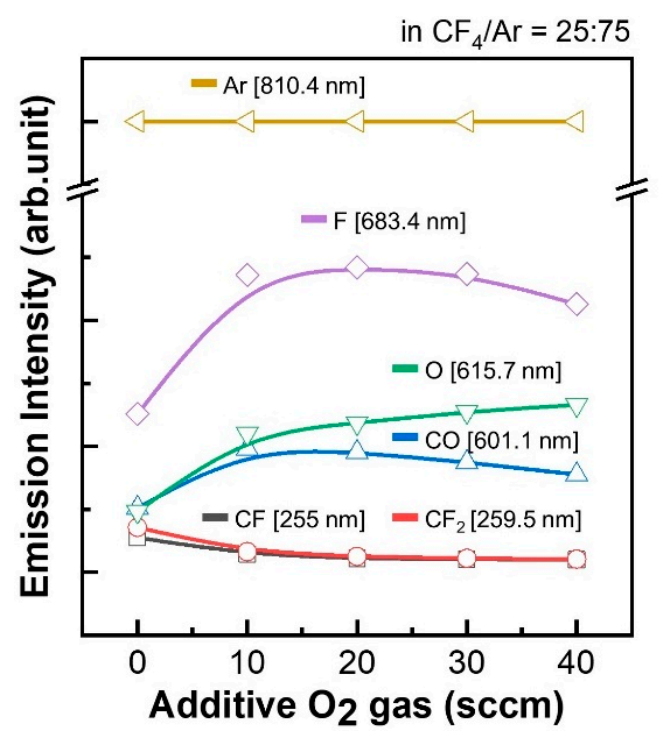

Figure 2. Results of OES analysis as a function of additive $\mathrm{O}_{2}$ gas flow rate with fixed $\mathrm{CF}_{4} / \mathrm{Ar}=25: 75 \mathrm{sccm}$.

Table 1. Electron-impact and gas-phase reactions in $\mathrm{O}_{2} / \mathrm{CF}_{4} / \mathrm{Ar}$ plasma.

\begin{tabular}{cc}
\hline Electron-Impact Reaction & Gas-Phase Reaction \\
\hline $\mathrm{e}+\mathrm{CF}_{4} \rightarrow \mathrm{CF}_{3}+\mathrm{F}+\mathrm{e}$ & $\mathrm{CF}_{3}+\mathrm{O} \rightarrow \mathrm{CF}_{2} \mathrm{O}+\mathrm{F}$ \\
\hline $\mathrm{e}+\mathrm{CF}_{4} \rightarrow \mathrm{CF}_{2}+2 \mathrm{~F}+\mathrm{e}$ & $\mathrm{CF}_{2}+\mathrm{O} \rightarrow \mathrm{CFO}+\mathrm{F}$ \\
\hline $\mathrm{e}+\mathrm{CF}_{4} \rightarrow \mathrm{CF}+3 \mathrm{~F}+\mathrm{e}$ & $\mathrm{CF}_{2}+\mathrm{O} \rightarrow \mathrm{CO}+2 \mathrm{~F}$ \\
\hline- & $\mathrm{CF}+\mathrm{O} \rightarrow \mathrm{CO}+\mathrm{F}$ \\
\hline
\end{tabular}

Thereafter, the $\mathrm{F}$ and $\mathrm{CO}$ decreased gradually as more $\mathrm{O}_{2}$ gas was added, which seems to be due to the increase in gas-phase reactions between the $\mathrm{F}$ and $\mathrm{CO}$ as follows:

$$
\mathrm{CO}+\mathrm{F} \rightarrow \mathrm{CFO}
$$

In the OES results, the trend of the emission intensity of $F$ followed that of the etch rate, shown in Figure 1, which means that the F were closely related to the chemical etching of the IGZO thin films.

Figure 3 shows the change in elemental composition at the IGZO thin film surface and the XPS narrow spectra of the $\mathrm{F} 1 \mathrm{~s}$ peak before and after the etching process. $\mathrm{F}$ was detected in the thin films etched in both $\mathrm{CF}_{4} / \mathrm{Ar}$ and $\mathrm{O}_{2} / \mathrm{CF}_{4} / \mathrm{Ar}$ plasmas, and the ratio of $\mathrm{F}$ decreased despite the higher etch rate for $\mathrm{O}_{2} / \mathrm{CF}_{4} / \mathrm{Ar}$ plasma. This means that etch residues on the thin-film surface were reduced. In the IGZO thin film etched using $\mathrm{O}_{2} / \mathrm{CF}_{4} / \mathrm{Ar}$ plasma, the ratio of $\mathrm{O}$, In, and $\mathrm{Ga}$ atoms was higher and the ratio of $\mathrm{Zn}$ atoms was slightly lower than those in the thin film etched using the $\mathrm{CF}_{4} /$ Ar plasma. Figure $3 \mathrm{~b}$ shows the XPS narrow-scan spectra of the F 1s peak. The peaks of the IGZO thin films etched using the $\mathrm{CF}_{4} / \mathrm{Ar}$ and $\mathrm{O}_{2} / \mathrm{CF}_{4} / \mathrm{Ar}$ plasmas were observed at 685 and $686 \mathrm{eV}$, respectively. This means that the $\mathrm{Zn}-\mathrm{F}$ reaction in the presence of $\mathrm{O}_{2}$ was more 
predominant than the In-F and Ga-F reactions under $\mathrm{CF}_{4} / \mathrm{Ar}$ plasma, which explains the lowering of the ratio of $\mathrm{Zn}$ atoms, indicated in Figure 3a [33].
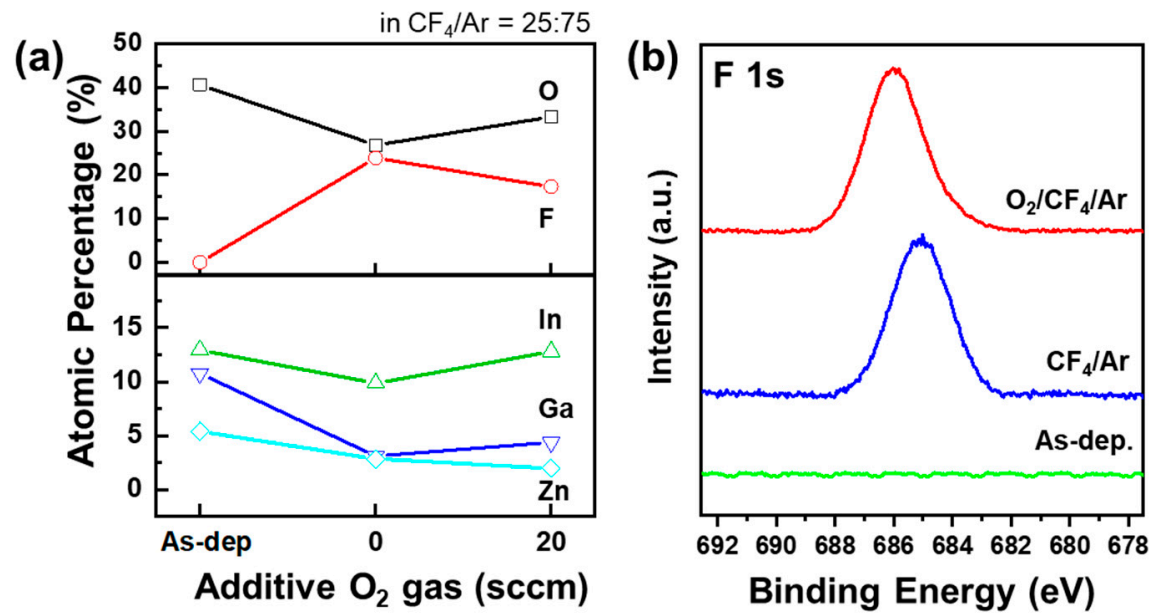

Figure 3. XPS analysis. (a) Chemical composition of IGZO thin film surface and (b) narrow spectra of $\mathrm{F} 1 \mathrm{~s}$ peak as a function of additive $\mathrm{O}_{2}$ gas flow rate with fixed $\mathrm{CF}_{4} / \mathrm{Ar}=25: 75 \mathrm{sccm}$.

Figure $4 \mathrm{a}-\mathrm{c}$ show the XPS narrow scan spectra for the oxygen $\mathrm{O}$ 1s peaks of the IGZO thin-film surface before and after the etching process, and each spectrum was deconvoluted into three peaks, a low peak (LP), middle peak (MP), and high peak (HP). The low peak centered at $530 \mathrm{eV}$ is ascribed to oxygen bonding with metal ions in the IGZO thin films, such as $\operatorname{In}_{x} \mathrm{O}_{y}, \mathrm{Ga}_{x} \mathrm{O}_{y}$, and $\mathrm{Zn}_{x} \mathrm{O}_{y}[34,35]$. The middle peak centered at $531.2 \mathrm{eV}$ is attributed to oxygen vacancies in the IGZO compound structure [36]. The high peak is related to chemisorbed or dissociated oxygen, absorbed $\mathrm{H}_{2} \mathrm{O}$, or $\mathrm{OH}$ groups at the surface $[37,38]$. Figure $4 \mathrm{~d}$ shows the atomic ratios corresponding to the low peak, middle peak, and high peak. In the case of etching using $\mathrm{CF}_{4} / \mathrm{Ar}$ plasma, the low peak's area decreased, whereas the areas of the middle peak and high peak increased. Furthermore, in the IGZO thin films etched using the $\mathrm{O}_{2} / \mathrm{CF}_{4} / \mathrm{Ar}$ plasma, the areas of the low peak and high peak were further lowered and increased, respectively; however, the middle peak's area was lower than that in the case of the thin film etched using $\mathrm{CF}_{4} /$ Ar. As the etching proceeded, the metal atoms of the IGZO structure reacted with the F in the plasma to break the bond with the oxygen, resulting in a decrease in the low peak's ratio. In particular, the reduction in the low peak's ratio was more prominent in the $\mathrm{O}_{2} / \mathrm{CF}_{4} / \mathrm{Ar}$ plasma, which entailed a high ratio of F. Oxygen atoms in the IGZO structure also broke the bonds with metals as etching proceeded; thus, the increase in the middle peak, high peak, and dissociated oxygens introduced oxygen vacancies. The IGZO thin film etched using the $\mathrm{O}_{2} / \mathrm{CF}_{4} / \mathrm{Ar}$ plasma had a lower middle peak ratio than the thin film etched using the $\mathrm{CF}_{4} / \mathrm{Ar}$ plasma because the reactive radicals in each plasma were different. In other words, oxygen atoms in the IGZO thin film were etched away in the form of $\mathrm{CFO}$ and $\mathrm{CO}$ by $\mathrm{CF}_{2}$ and $\mathrm{CF}$ in the $\mathrm{CF}_{4}$ / Ar plasma, as shown in Table 1 . By contrast, $\mathrm{CF}_{3}, \mathrm{CF}_{2}$, and $\mathrm{CF}$ were already converted into $\mathrm{CFO}$ and $\mathrm{CO}$ in the $\mathrm{O}_{2} / \mathrm{CF}_{4} / \mathrm{Ar}$ plasma before reacting with oxygen on the surface of the thin film; thus, the reaction rate with oxygen atoms in the IGZO thin film decreased.

After etching, the work function of the oxide semiconductor surface may change owing to the stoichiometric ratio, etching residues, oxygen vacancies, etc. Therefore, we performed a UPS analysis to confirm the effect of the plasma etching process on the work function of the IGZO thin film. Figure $5 \mathrm{a}, \mathrm{b}$ show the secondary electron cutoff and valence band edge region of the IGZO thin film. The work function $(\phi)$ was calculated using the following equation:

$$
\phi=h v-\left(E_{\text {fermi }}-E_{\text {cutoff }}\right)
$$

where $h v$ is the photon energy, $E_{\text {cutoff }}$ is the secondary electron cutoff energy, and $E_{\text {fermi }}$ is the Fermi level energy. The value of $h v$ is $21.22 \mathrm{eV}$ in the case of He(I) radiation. In 
addition, the UPS spectra were calibrated using Au with a binding energy $8.05 \mathrm{eV}$. The work functions of the as-deposited IGZO thin film, IGZO thin film etched in $\mathrm{CF}_{4} / \mathrm{Ar}$ plasma, and IGZO thin film etched in $\mathrm{O}_{2} / \mathrm{CF}_{4} / \mathrm{Ar}$ plasma were 4.776, 4.592, and $4.872 \mathrm{eV}$, respectively, as shown in Figure 5c. Here, the maximum difference in the work function was $280 \mathrm{meV}$. When the IGZO thin film was etched using the $\mathrm{CF}_{4} /$ Ar plasma, the work function decreased. By contrast, when the IGZO thin film was etched using the $\mathrm{O}_{2} / \mathrm{CF}_{4} / \mathrm{Ar}$ plasma, the work function increased. This result indicates that the change in the work function of IGZO thin films is caused not only by oxygen vacancies, but also by several other factors such as the stoichiometry of the IGZO structure and etching residues on the thin film surface [39-41]. Figure 5d and Figure S2 show the KPFM images for the differences in the work functions; these images support the results of the UPS analysis.
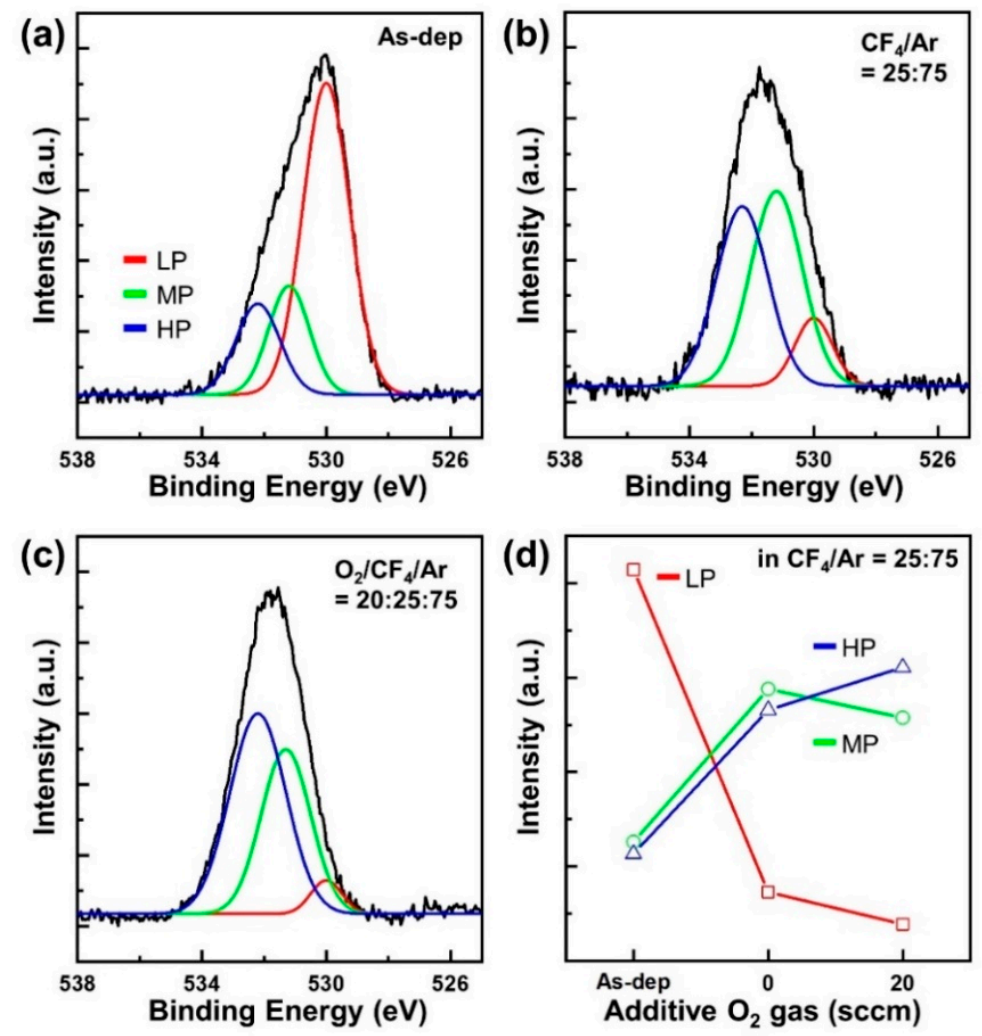

Figure 4. (a-c) O 1s peaks of XPS narrow-scan spectra of the IGZO thin film and (d) intensity corresponding to low peak, middle peak and high peak as a function of additive $\mathrm{O}_{2}$ flow rate with fixed $\mathrm{CF}_{4} / \mathrm{Ar}=25: 75 \mathrm{sccm}$. LP, MP, and HP mean low peak $(530 \mathrm{eV})$, middle peak $(531.2 \mathrm{eV})$, and high peak $(532.2 \mathrm{eV})$.

Considering that IGZO is used as an active layer in OSTFTs and needs to be bonded with neighboring elements, such as the metals of the source and drain electrodes, the adhesion of the etched IGZO must be considered as an important factor in the fabrication. Therefore, contact angle measurements were performed to measure the surface energy before and after etching. As shown in Figure 6, all samples etched by the $\mathrm{CF}_{4} / \mathrm{Ar}$ and $\mathrm{O}_{2} / \mathrm{CF}_{4} / \mathrm{Ar}$ plasmas exhibited lower contact angles compared to the as-deposited IGZO thin film (i.e., $109.96^{\circ}, 96.92^{\circ}$, and $103.37^{\circ}$ for as-deposited, etched using $\mathrm{CF}_{4} / \mathrm{Ar}=25: 75 \mathrm{sccm}$, and etched using $\mathrm{O}_{2} / \mathrm{CF}_{4} / \mathrm{Ar}=20: 25: 75 \mathrm{sccm}$, respectively). We confirmed that the HP's area increased after etching, as shown in Figure 4. This indicates the presence of chemically absorbed or dissociated oxygen on the IGZO surface after etching. The chemically absorbed or dissociated oxygen endows the surface. This surface has high surface energy, which indicates a strong molecular attraction [42,43]. As a result, the IGZO thin films etched using $\mathrm{CF}_{4} / \mathrm{Ar}$ and $\mathrm{O}_{2} / \mathrm{CF}_{4} / \mathrm{Ar}$ plasmas show a higher surface energy than that of the 
as-deposited IGZO thin film; thus, the etched thin films exhibit higher adhesions compared to that of the as-deposited film.
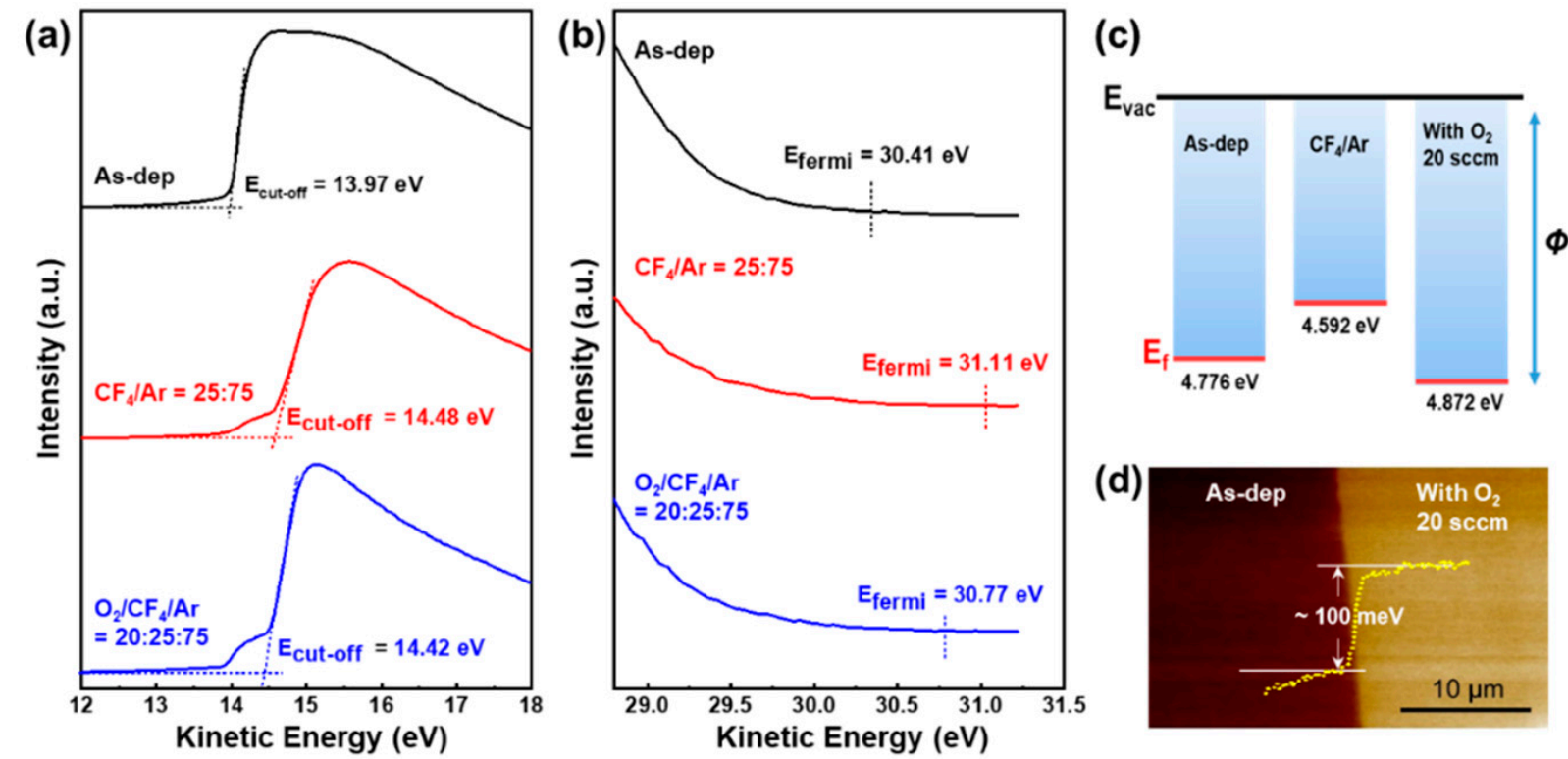

Figure 5. UPS spectra of (a) secondary electron cutoff $\left(E_{\text {cut-off }}\right)(\mathbf{b})$ Fermi level energy $\left(E_{\text {fermi }}\right)$ region. (c) Bar charts for variations of the work function of IGZO thin films, depending on the etching condition and (d) KPFM image to compare as-deposited thin-films and those etched using $\mathrm{O}_{2} / \mathrm{CF}_{4} / \mathrm{Ar}$ plasma.
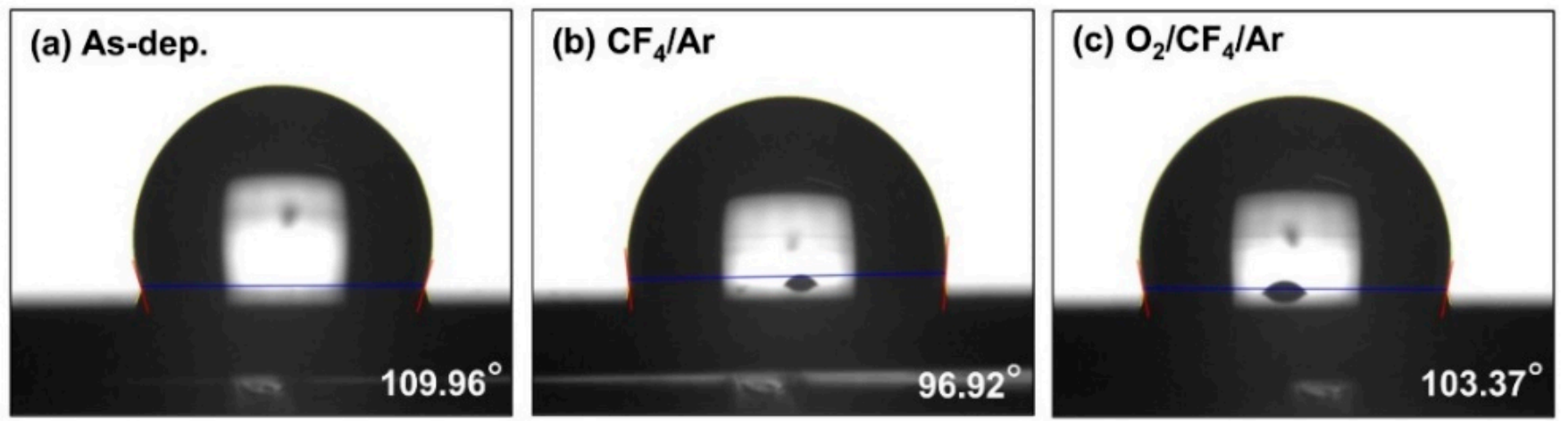

Figure 6. Contact angle value and droplet profiles of IGZO thin film surfaces as a function of additive $\mathrm{O}_{2}$ concentration with fixed $\mathrm{CF}_{4} / \mathrm{Ar}=25: 75 \mathrm{sccm}$. (a) As-deposited IGZO thin film; IGZO thin film etched using (b) $\mathrm{CF}_{4} / \mathrm{Ar}$ plasma and (c) $\mathrm{O}_{2} / \mathrm{CF}_{4} /$ Ar plasma.

The surface roughness of the IGZO thin films must also be considered because the roughness affects the device performance, such as the gate leakage current, and postprocesses, such as S/D metallization [44]. Figure 7 shows the AFM images of the as-deposited and etched IGZO thin films, where the surface roughness increased slightly to $0.0732 \mathrm{~nm}$ after $\mathrm{CF}_{4} / \mathrm{Ar}$ plasma etching. By contrast, the surface roughness after etching using $\mathrm{O}_{2} / \mathrm{CF}_{4} /$ Ar plasma $(0.0645 \mathrm{~nm})$ is comparable to that of the as-deposited IGZO thin films. It is considered that the increased surface roughness of the thin film etched in $\mathrm{CF}_{4} / \mathrm{Ar}$ plasma is due to the surface residues mentioned in the XPS analysis. In other words, it is considered that the surface roughness decreased as the surface residues were reduced in the thin film etched in the $\mathrm{O}_{2} / \mathrm{CF}_{4} / \mathrm{Ar}$ plasma. These changes are so subtle that it can be concluded that the surface roughness remains the same even after etching using $\mathrm{O}_{2} / \mathrm{CF}_{4} /$ Ar plasma. 
(a) As-dep.

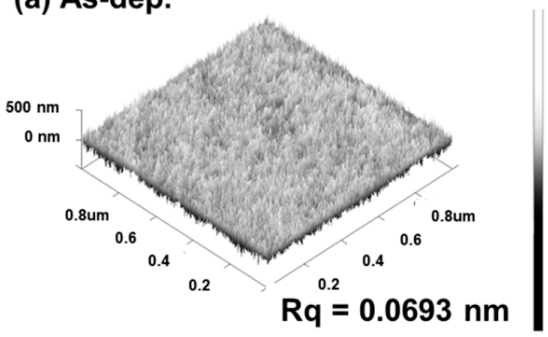

(b) $\mathrm{CF}_{4} / \mathrm{Ar}$

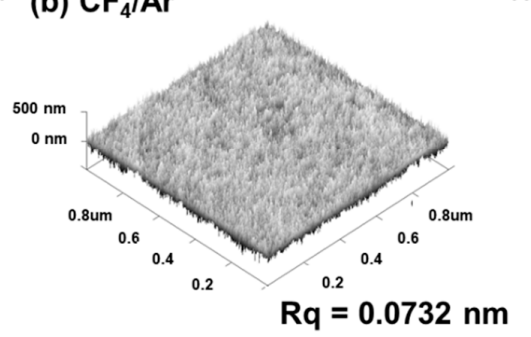

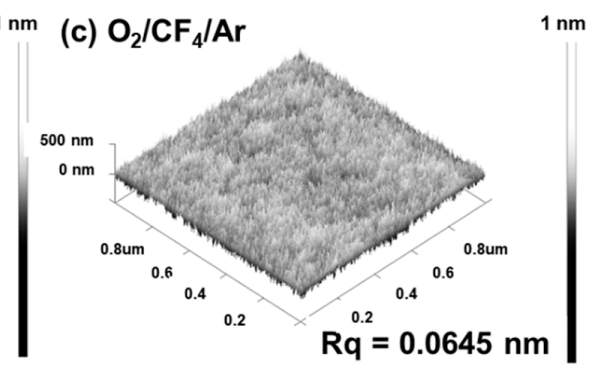

Figure 7. AFM image and root-mean-square values of roughness as a function of additive $\mathrm{O}_{2}$ gas with fixed $\mathrm{CF}_{4} / \mathrm{Ar}=25: 75 \mathrm{sccm}$. (a) As-deposited IGZO thin film; IGZO thin film etched (b) using $\mathrm{CF}_{4} / \mathrm{Ar}$ plasma and (c) using $\mathrm{O}_{2} / \mathrm{CF}_{4} /$ Ar plasma.

\section{Conclusions}

In this study, we observed the etch characteristics of an IGZO thin film and the change in the surface characteristics after etching with the addition of $\mathrm{O}_{2}$ in $\mathrm{CF}_{4} / \mathrm{Ar}$-based $\mathrm{ACP}$ system. The highest etch rate was $32.7 \mathrm{~nm} / \mathrm{min}$ using a plasma with an $\mathrm{O}_{2} / \mathrm{CF}_{4} / \mathrm{Ar}$ gas mixing ratio of 20:25:75 sccm. We confirmed through XPS and OES analyses that the etch residue of the IGZO thin films decreased as $\mathrm{O}_{2}$ was added to the $\mathrm{CF}_{4} / \mathrm{Ar}$ plasma. The work function of the IGZO thin films decreased upon etching in $\mathrm{CF}_{4} / \mathrm{Ar}$ plasma and increased after etching in $\mathrm{CF}_{4} / \mathrm{Ar}$ plasma with $\mathrm{O}_{2}$ gas addition. The surface energy increased for IGZO thin films etched in $\mathrm{CF}_{4} / \mathrm{Ar}$ and $\mathrm{O}_{2} / \mathrm{CF}_{4} / \mathrm{Ar}$ plasmas. The surface energy was the highest when $\mathrm{CF}_{4} /$ Ar plasma was employed for etching. $\mathrm{CF}_{4}$-based plasma etching did not significantly affect the surface roughness. We expect these results to considerably contribute to research on next-generation devices and processes.

Supplementary Materials: The following are available online at https:/ /www.mdpi.com/article/10 .3390 / coatings11080906/s1.docx, Figure S1: Etch rate of IGZO thin films as a function of $\mathrm{CF}_{4} / \mathrm{Ar}$ mixing ratio, Figure S2: KPFM image comparing as-deposited thin films and IGZO thin films etched using $\mathrm{CF}_{4} /$ Ar plasma.

Author Contributions: Conceptualization, C.-Y.L., D.-S.U., and C.-I.K.; methodology, C.-Y.L. and Y.-H.J., D.-S.U. and C.-I.K.; software, C.-Y.L. and Y.-H.J.; validation, C.-Y.L., Y.-H.J. and M.P.K.; formal analysis, C.-Y.L., Y.-H.J. and M.P.K.; data curation, C.-Y.L., and M.P.K. and D.-S.U.; writingoriginal draft preparation, C.-Y.L.; writing-review and editing, D.-S.U. and C.-I.K.; visualization, C.-Y.L., Y.-H.J., M.P.K. and D.-S.U.; supervision, D.-S.U. and C.-I.K.; project administration, C.-I.K.; funding acquisition, D.-S.U. and C.-I.K. All authors have read and agreed to the published version of the manuscript.

Funding: This work was supported by the National Research Foundation (NRF) of Korea (2018R1D1 A1B07051429 and 2020R1G1A1102692).

Institutional Review Board Statement: Not applicable.

Informed Consent Statement: Not applicable.

Data Availability Statement: Not applicable.

Conflicts of Interest: The authors declare no conflict of interest.

\section{References}

1. Wager, J.F.; Hoffman, R. Thin, fast, and flexible. IEEE Spectr. 2011, 48, 42-56. [CrossRef]

2. Troughton, J.G.; Downs, P.; Price, R.; Atkinson, D. Densification of a-IGZO with low-temperature annealing for flexible electronics applications. Appl. Phys. Lett. 2017, 110, 011903. [CrossRef]

3. Sheng, J.; Hong, T.; Lee, H.M.; Kim, K.; Sasase, M.; Kim, J.; Hosono, H.; Park, J.S. Amorphous IGZO TFT with high mobility of similar to $70 \mathrm{~cm}^{2} /(\mathrm{V} \mathrm{s})$ via vertical dimension control using PEALD. ACS Appl. Mater. Interfaces 2019, 11, 40300-40309. [CrossRef]

4. Choi, I.M.; Kim, M.J.; On, N.; Song, A.; Chung, K.B.; Jeong, H.; Park, J.K.; Jeong, J.K. Achieving high mobility and excellent stability in amorphous In-Ga-Zn-Sn-O thin-film transistors. IEEE Trans. Electron Devices 2020, 67, 1014-1020. [CrossRef] 
5. Kim, J.; Park, J.; Yoon, G.; Khushabu, A.; Kim, J.-S.; Pae, S.; Cho, E.-C.; Yi, J. Effect of IGZO thin films fabricated by Pulsed-DC and RF sputtering on TFT characteristics. Mater. Sci. Semicond. Process. 2020, 120, 105264. [CrossRef]

6. Alford, T.L.; Gadre, M.J.; Vemuri, R.N.P. Improved mobility and transmittance of room-temperature-deposited amorphous indium gallium zinc oxide (a-IGZO) films with low-temperature postfabrication anneals. JOM 2013, 65, 519-524. [CrossRef]

7. Lee, E.G.; Park, J.; Lee, S.-E.; Na, H.-J.; Cho, N.-K.; Im, C.; Cho, Y.H.; Kim, Y.S. Oxygen radical control via atmospheric pressure plasma treatment for highly stable IGZO thin-film transistors. IEEE Trans. Electron Devices 2020, 67, 3135-3140. [CrossRef]

8. Hoshino, K.; Hong, D.; Chiang, H.Q.; Wager, J.F. Constant-voltage-bias stress testing of a-IGZO thin-film transistors. IEEE Trans. Electron Devices 2009, 56, 1365-1370. [CrossRef]

9. Lee, J.H.; Kim, D.H.; Yang, D.J.; Hong, S.Y.; Yoon, K.S.; Hong, P.S.; Jeong, C.O.; Park, H.S.; Kim, S.Y.; Lim, S.K.; et al. World's largest (15-inch) XGA AMLCD panel using IGZO oxide TFT. SID Int. Symp. Dig. Tech. 2008, 39, 625-628. [CrossRef]

10. Nomura, K.; Aoki, T.; Nakamura, K.; Kamiya, T.; Nakanishi, T.; Hasegawa, T.; Kimura, M.; Kawase, T.; Hirano, M.; Hosono, H. Three-dimensionally stacked flexible integrated circuit: Amorphous oxide/polymer hybrid complementary inverter using n-type a-In-Ga-Zn-O and p-type poly-(9,9-dioctylfluorene-co-bithiophene) thin-film transistors. Appl. Phys. Lett. 2010, 96, 263509. [CrossRef]

11. Oian, Z.; Ruan, C.; Xia, G.; Gong, H.; Wang, S. Low-temperature solution-processed InGaZnO thin film transistors by using lightwave-derived annealing. Thin Solid Film. 2021, 723, 138594.

12. Benwadih, M.; Coppard, R.; Bonrad, K.; Klyszcz, A.; Vuillaume, D. High mobility flexible amorphous IGZO thin-film transistors with a low thermal budget ultra-violet pulsed light process. ACS Appl. Mater. Interfaces 2016, 8, 34513-34519. [CrossRef]

13. Knobelspies, S.; Takabayashi, A.; Daus, A.; Cantarella, G.; Munzenrieder, N.; Troster, G. Improvement of contact resistance in flexible a-IGZO thin-film transistors by $\mathrm{CF}_{4} / \mathrm{O}_{2}$ plasma treatment. Solid State Electron. 2018, 150, 23-27. [CrossRef]

14. Wei, S.; Wang, F.; Zou, X.; Wang, L.; Liu, C.; Liu, X.; Hu, W.; Fan, Z.; Ho, J.C.; Liao, L. Flexible quasi-2D perovskite/IGZO phototransistors for ultrasensitive and broadband photodetection. Adv. Mater. 2019, 32, e1907527. [CrossRef]

15. Lee, S.; Song, Y.; Park, H.; Zaslavsky, A.; Paine, D.C. Channel scaling and field-effect mobility extraction in amorphous InZnO thin film transistors. Solid State Electron. 2017, 135, 94-99. [CrossRef]

16. Cho, E.N.; Kang, J.H.; Yun, I. Contact resistance dependent scaling-down behavior of amorphous InGaZnO thin-film transistors. Curr. Appl. Phys. 2011, 11, 1015-1019. [CrossRef]

17. Zheng, Y.; Li, G.; Wang, W.; Li, X.; Jiang, Z. Dry Etching characteristics of amorphous indium-gallium-zinc-oxide thin films. Plasma Sci. Technol. 2012, 14, 915-918. [CrossRef]

18. Kim, K.; Efremov, A.; Lee, J.; Kwon, K.H.; Yeom, G.Y. Etching mechanisms of (In, Ga, Zn)O thin films in $\mathrm{CF}_{4} / \mathrm{Ar} / \mathrm{O}_{2}$ inductively coupled plasma. J. Vac. Sci. Technol. A 2015, 33, 031601. [CrossRef]

19. Park, W.; Whang, K.W.; Yoon, Y.G.; Kim, J.H.; Rha, S.H.; Hwang, C.S. High rate dry etching of $\mathrm{InGaZnO}$ by $\mathrm{BCl}_{3} / \mathrm{O}_{2} \mathrm{plasma}$. Appl. Phys. Lett. 2011, 99, 062110. [CrossRef]

20. Park, J.C.; Jeong, O.G.; Kim, J.K.; Yun, Y.H.; Pearton, S.J.; Cho, H. Comparison of chlorine- and fluorine-based inductively coupled plasmas for dry etching of $\mathrm{InGaZnO}_{4}$ films. Thin Solid Film. 2013, 546, 136-140. [CrossRef]

21. Joo, Y.H.; Jin, M.J.; Kim, S.K.; Um, D.S.; Kim, C.I. BCl 3 / Ar plasma etching for the performance enhancement of Al-doped ZnO thin films. Appl. Surf. Sci. 2021, 516, 149957. [CrossRef]

22. Lin, D.; Su, W.C.; Chang, T.C.; Chen, H.C.; Tu, Y.F.; Zhou, K.J.; Hung, Y.H.; Yang, J.; Nu, I.N.; Tsai, T.M.; et al. Degradation behavior of etch-stopper-layer structured a-InGaZnO thin-film transistors under hot-carrier stress and illumination. IEEE Trans. Electron Devices 2021, 68, 556-559. [CrossRef]

23. Ravi, S.K.; Sun, W.X.; Nandakumar, D.K.; Zhang, Y.X.; Tan, S.C. Optical manipulation of work function contrasts on metal thin films. Sci. Adv. 2018, 4, eaao6050. [CrossRef]

24. Joo, Y.H.; Wi, J.H.; Lee, W.J.; Chung, Y.D.; Cho, D.H.; Kang, S.; Um, D.S.; Kim, C.I. Work function tuning of zinc-tin oxide thin films using high-density $\mathrm{O}_{2}$ plasma treatment. Coatings 2020, 10, 1026. [CrossRef]

25. Wandelt, K. The local work function: Concept and implications. Appl. Surf. Sci. 1997, 111, 1-10. [CrossRef]

26. Kim, M.; Jeong, J.H.; Lee, H.J.; Ahn, T.K.; Shin, H.S.; Park, J.S.; Jeong, J.K.; Mo, Y.G.; Kim, H.D. High mobility bottom gate InGaZnO thin film transistors with SiOx etch stopper. Appl. Phys. Lett. 2007, 90, 212114. [CrossRef]

27. Joo, Y.H.; Kim, C.I. High-density plasma etching characteristics of indium-gallium-zinc oxide thin films in $\mathrm{CF}_{4} / \mathrm{Ar}$ plasma. Thin Solid Film. 2015, 583, 40-45. [CrossRef]

28. Na, J.H.; Kitamura, M.; Arakawa, Y. High field-effect mobility amorphous InGaZnO transistors with aluminum electrodes. Appl. Phys. Lett. 2008, 93, 063501. [CrossRef]

29. Lee, J.S.; Chang, S.; Koo, S.M.; Lee, S.Y. High-performance a-IGZO TFT with $\mathrm{ZrO}_{2}$ gate dielectric fabricated at room temperature. IEEE Electron. Device Lett. 2010, 31, 225-227.

30. Akatsuka, H. Optical Emission Spectroscopic (OES) analysis for diagnostics of electron density and temperature in nonequilibrium argon plasma based on collisional-radiative mode. Adv. Phys. X 2019, 4, 1592707. [CrossRef]

31. Lim, N.; Efremov, A.; Yeom, G.Y.; Kwon, K.H. On the etching characteristics and mechanisms of $\mathrm{HfO}_{2}$ thin films in $\mathrm{CF}_{4} / \mathrm{O}_{2} / \mathrm{Ar}$ and $\mathrm{CHF}_{3} / \mathrm{O}_{2} /$ Ar plasma for nano-devices. J. Nanosci. Nanotechnol. 2014, 14, 9670-9679. [CrossRef]

32. Nantel-Valiquette, M.; Kabouzi, Y.; Castanos-Martinez, E.; Makasheva, K.; Moisan, M.; Rostaing, J.C. Reduction of perfluorinated compound emissions using atmospheric pressure microwave plasmas: Mechanisms and energy efficiency. Pure Appl. Chem. 2006, 78, 1173-1185. [CrossRef] 
33. Kawamoto, Y.; Ogura, K.; Shojiya, M.; Takahashi, M.; Kadono, K. F-1s XPS of fluoride glasses and related fluoride crystals. J. Fluor. Chem. 1999, 96, 135-139. [CrossRef]

34. Cebulla, R.; Wendt, R.; Ellmer, K. Al-doped zinc oxide films deposited by simultaneous rf and dc excitation of a magnetron plasma: Relationships between plasma parameters and structural and electrical film properties. J. Appl. Phys. 1998, 83, 1087-1095. [CrossRef]

35. Coppa, B.J.; Davis, R.F.; Nemanich, R.J. Gold Schottky contacts on oxygen plasma-treated, n-type ZnO(000over-bar). Appl. Phys. Lett. 2003, 82, 400-402. [CrossRef]

36. Wang, Z.G.; Zu, X.T.; Zhu, S.; Wang, L.M. Green luminescence originates from surface defects in ZnO nanoparticles. Physica E 2006, 35, 199-202. [CrossRef]

37. Islam, M.N.; Ghosh, T.B.; Chopra, K.L.; Acharya, H.N. XPS and X-ray diffraction studies of aluminum-doped zinc oxide transparent conducting films. Thin Solid Film. 1996, 280, 20-25. [CrossRef]

38. Dupin, J.C.; Gonbeau, D.; Vinatier, P.; Levasseur, A. Systematic XPS studies of metal oxides, hydroxides and peroxides. Phys. Chem. Chem. Phys. 2000, 2, 1319-1324. [CrossRef]

39. Greiner, M.T.; Chai, L.; Helander, M.G.; Tang, W.M.; Lu, Z.H. Transition metal oxide work functions: The influence of cation oxidation state and oxygen vacancies. Adv. Funct. Mater. 2012, 22, 4557-4568. [CrossRef]

40. Yoon, Y.S.; Jee, S.H.; Kakati, N.; Maiti, J.; Kim, D.J.; Lee, S.H.; Yoon, H.H. Work function effects of ZnO thin film for acetone gas detection. Ceram. Int. 2012, 38, S653-S656. [CrossRef]

41. Wang, W.Y.; Feng, Q.Y.; Jiang, K.M.; Huang, J.H.; Zhang, X.P.; Song, W.J.; Tan, R.Q. Dependence of aluminum-doped zinc oxide work function on surface cleaning method as studied by ultraviolet and X-ray photoelectron spectroscopies. Appl. Surf. Sci. 2011, 257, 3884-3887. [CrossRef]

42. Jeong, J.H.; Yang, H.W.; Park, J.S.; Jeong, J.K.; Mo, Y.G.; Kim, H.D.; Song, J.; Hwang, C.S. Origin of subthreshold swing improvement in amorphous indium gallium zinc oxide transistors. Solid State Electrochem. 2008, 11, H157-H159. [CrossRef]

43. Cho, Y.C.; Cha, S.Y.; Shin, J.M.; Park, J.H.; Park, S.E.; Cho, C.R.; Park, S.; Pak, H.K.; Jeong, S.Y.; Lim, A.R. The conversion of wettability in transparent conducting Al-doped ZnO thin film. Solid State Commun. 2009, 149, 609-611. [CrossRef]

44. Chan, A.B.Y.; Nguyen, C.T.; Ko, P.K.; Chan, S.T.H.; Wong, S.S. Polished TFT's: Surface roughness reduction and its correlation to device performance improvement. IEEE Trans. Electron. Devices 1997, 44, 455-463. [CrossRef] 